\title{
Efficacy, safety and feasibility of fosaprepitant for the prevention of chemotherapy-induced nausea and vomiting in pediatric patients receiving moderately and highly emetogenic chemotherapy - results of a non- interventional observation study
}

Semjon Willier ${ }^{1}$, Karin Melanie Cabanillas Stanchi ${ }^{2}$, Martina von Have ${ }^{1}$, Vera Binder ${ }^{1}$, Franziska Blaeschke ${ }^{1}$, Judith Feucht ${ }^{2}$, Tobias Feuchtinger ${ }^{1}$ and Michaela Döring ${ }^{2^{*}}$ (D)

\footnotetext{
Abstract

Background: Chemotherapy-induced nausea and vomiting (CINV) belong among the most burdensome side effects in hemato-oncology. Mostly, a combination of ondansetron and dexamethasone is used as antiemetic prophylaxis in pediatric patients undergoing emetogenic chemotherapy. However, dexamethasone is prohibited in different pediatric chemotherapy protocols. Currently, data on the use of ondansetron with the new antiemetic agent fosaprepitant without dexamethasone is not available for pediatric patients.

Methods: In this non-interventional observation study, 79 pediatric patients with a median age of 8.0 years (range 0.5-17.9 years) who received a CINV prophylaxis regimen with either fosaprepitant (4 mg/kg; maximum $150 \mathrm{mg}$ ) and ondansetron (as 24- $h$ continuous infusion) ( $n=40$; fosaprepitant group/FG) or ondansetron only ( $n=39$; control group/CG) during moderately or highly emetogenic chemotherapy were analyzed. The groups were analyzed and compared for frequency of vomiting, administered doses of on-demand antiemetic dimenhydrinate and adverse events during the acute (0-24 h after chemotherapy administration) and delayed (> $24 \mathrm{~h}-120 \mathrm{~h}$ ) CINV phases.

\footnotetext{
* Correspondence: michaela.doering@med.uni-tuebingen.de

${ }^{2}$ Department I - General Paediatrics, Haematology/Oncology, University

Children's Hospital Tübingen, Hoppe-Seyler-Str. 1, 72076 Tübingen, Germany

Full list of author information is available at the end of the article
}

(c) The Author(s). 2019 Open Access This article is distributed under the terms of the Creative Commons Attribution 4.0 International License (http://creativecommons.org/licenses/by/4.0/), which permits unrestricted use, distribution, and reproduction in any medium, provided you give appropriate credit to the original author(s) and the source, provide a link to the Creative Commons license, and indicate if changes were made. The Creative Commons Public Domain Dedication waiver (http://creativecommons.org/publicdomain/zero/1.0/) applies to the data made available in this article, unless otherwise stated. 
(Continued from previous page)

Results: A total of 112 and 116 chemotherapy blocks were analyzed in the fosaprepitant and the control group, respectively. The emetogenic potential of the administered chemotherapy did not significantly differ $(p=0.8812)$ between the two cohorts. In the acute CINV phase, the percentage of patients experiencing vomiting $(n=26$ patients) and the vomiting events were significantly higher ( $p=0.0005$ and $p<0.0001$, respectively) in the CG ( $n=$ 26 patients (66.7\%); 88 events) compared with the FG ( $n=10$ patients (25.0\%); 37 events). In the delayed CINV phase, the percentage of patients experiencing vomiting and the vomiting events were also significantly higher ( $p=0.0017$ and $p<0.0001$, respectively) in the CG $(n=31$ patients (79.5\%); 164 events) compared with the FG $(n=$ 17 patients (42.5\%); 103 events). Additionally, significantly more dimenhydrinate doses were administered in the CG compared with the FG patients $(n=322 / n=198 ; p<0.0001)$. The occurrence of adverse events did not significantly differ between the two groups $(p>0.05)$.

Conclusion: Fosaprepitant $(4.0 \mathrm{mg} / \mathrm{kg})$ in addition to ondansetron, without application of dexamethasone, was well tolerated, safe, effective and superior to ondansetron only as CINV prophylaxis in pediatric patients during moderately and highly emetogenic chemotherapy.

Keywords: Fosaprepitant, Aprepitant, Pediatric patients, Emetogenic chemotherapy, Chemotherapy-induced nausea and vomiting, Ondansetron, Antiemetic prophylaxis, ALL, Non-interventional observation study

\section{Background}

Chemotherapy-induced nausea and vomiting (CINV) is the most common and the most burdensome side effect associated with anti-cancer treatment. Especially in pediatric patients, this chemotherapy-related adverse event poses a significant impact on the quality of life [1].

During emetogenic chemotherapy, receptors of specific regions of the vomiting center of the brain may be activated. These receptors are usually bound by three different neurotransmitters: serotonin (5-hydroxytryptamine-3 receptor $\left(5-\mathrm{HT}_{3} \mathrm{R}\right)$ ), substance $\mathrm{P}$ (neurokinin-1 receptor $\left(N_{1} R\right)$ and dopamine $\left(D_{2}\right.$ receptor), inducing peripherally- or centrally-caused nausea and vomiting. CINV may occur within the first $24 \mathrm{~h}$ (acute phase) or 24 to $120 \mathrm{~h}$ (delayed phase) after the administration of chemotherapy [1].

Fosaprepitant is a water-soluble prodrug that is converted to aprepitant, which selectively antagonizes the $\mathrm{NK}_{1} \mathrm{R}$. In several clinical trials, aprepitant and fosaprepitant have proven effective in both the acute and delayed phases of CINV in adult and pediatric patients [2-4]. Compared with aprepitant formulations (capsules, suspension), fosaprepitant can be administered intravenously (IV) due to its hydrophilic qualities. Fosaprepitant is administered once prior to chemotherapy and every 5 days thereafter, compared with oral administration of aprepitant on three consecutive days starting on the first day of chemotherapy administration [5]. These advantages of the IV formulation hold strong importance especially in patients who are unable or unwilling to take oral formulations due to their low age or during mucositis.

A recently-published placebo-controlled trial has shown favorable results of a CINV prophylaxis regimen with fosaprepitant, ondansetron and dexamethasone in pediatric patients under 12 years of age receiving moderately or highly emetogenic chemotherapy for the treatment of hematologic and oncologic malignancies [4].

The current MASCC/ESMO (Multinational Association of Supportive Care in Cancer/European Society for Medical Oncology) guidelines recommend an antiemetic prophylaxis regimen with a $5-\mathrm{HT}_{3} \mathrm{R}$ antagonist plus the $\mathrm{NK}_{1} \mathrm{R}$ antagonist aprepitant plus dexamethasone for pediatric patients during moderately to highly emetogenic chemotherapy [5]. However, due to concerns regarding the immunosuppressive effects increasing the risk of infection (e.g. fungal infections) and interferences with the distribution of chemotherapy through the blood-brain barrier and apoptotic processes, dexamethasone is prohibited in several pediatric chemotherapy protocols $[5,6]$.

Until October 2015, the standard antiemetic prophylaxis regimen of the children's hospital where the study was conducted included ondansetron only as a 24-h continuous infusion and additional pro re nata (PRN) medication with dimenhydrinate. Due to excellent results regarding the efficacy and safety of CINV prophylaxis with fosaprepitant in adult patients [2] and initial studies in pediatric patients [7], the CINV prophylaxis strategy for pediatric patients receiving moderately to highly emetogenic chemotherapy was gradually expanded with single-dose fosaprepitant. Initially, older children $\geq 12$ years of age received fosaprepitant. After a good tolerability was seen in these patients, younger children $\geq 6$ and then $\geq 2$ years and $\geq 0.5$ years of age were gradually changed to a fosaprepitant-based regimen. Due to the very good clinical experience with fosaprepitant, the standard CINV prophylaxis regimen 
for these patients was changed to fosaprepitant plus ondansetron in 2015. In April 2018, the US Food and Drug Administration approved fosaprepitant as CINV prophylaxis and therapy in pediatric patients between 0.5 and 17 years of age [8].

The primary objective of this non-interventional observation study was to evaluate the efficacy, safety and feasibility of an antiemetic prophylaxis regimen with single-dose fosaprepitant plus ondansetron without dexamethasone in pediatric hemato-oncological patients in routine clinical practice in comparison with a standard regimen with ondansetron only for the prevention of CINV caused by moderately and highly emetogenic chemotherapy.

\section{Methods}

\section{Study design}

This non-interventional observational study analyzed data of pediatric patients between 0.5 and 17 years of age who were treated at the Department of Pediatric Hematology and Oncology at the Dr. von Hauner Children's Hospital, Germany between November 2015 and August 2016 receiving one or more chemotherapy courses for the treatment of hemato-oncological diseases according to pediatric oncology protocols.

The EP of the administered chemotherapeutic agent (in \% frequency of emesis in absence of prophylaxis) was defined as: minimal, stage $1(<10 \%) \mid$ low, stage $2(10$ $<30 \%) \mid$ moderate, stage $3(30-90 \%)$ | high, stage 4 (> 90\%) [9]. The EP of each chemotherapy course was defined by the administered agent with the highest EP $(\geq 3$; compare Table 3).

Inclusion criteria were age at the time of chemotherapy administration between $0.5-17$ years, administration of chemotherapy with a moderately or highly emetogenic potential (stage 3-4) during an in-patient stay, antiemetic prophylaxis with ondansetron only or ondansetron plus single-dose fosaprepitant.

Exclusion criteria were vomiting in the $24 \mathrm{~h}$ prior to the start of emetogenic chemotherapy, (additional) medication with aprepitant, granisetron, or dexamethasone, allergy to $\mathrm{NK}_{1}$ or $5-\mathrm{HT}_{3}$-antagonists, congestive heart failure, abnormal liver (AST and ALT > 2.5-fold of the upper normal limit) or kidney (serum creatinine $>2.5$ fold of the upper normal limit) function in the $24 \mathrm{~h}$ prior to the start of emetogenic chemotherapy, and scheduled hematopoietic stem cell transplantation.

All patients who met the inclusion criteria and received single-dose fosaprepitant and 24-h continuous infusion with ondansetron between November 2015 and August 2016 were consecutively enrolled in the fosaprepitant group (FG; $n=40$ ). All patients who met the inclusion criteria and received CINV prophylaxis with ondansetron only between November 2014 and October
2015 were consecutively enrolled in the control group (CG; $n=39$ ).

The analysis period with fosaprepitant and/or ondansetron included the time between the start of antiemetic prophylaxis until $120 \mathrm{~h}$ after starting the first moderately or highly emetogenic agent of each chemotherapy course.

The acute CINV phase of each chemotherapy course was defined as the first $24 \mathrm{~h}$ after the first application of a moderately or highly emetogenic agent. The delayed CINV phase was defined as the subsequent $96 \mathrm{~h}$ ( $>24-$ $120 \mathrm{~h}$ after administration of the first moderately or highly emetogenic agent).

Primary endpoints were the assessment of the efficacy (frequency of vomiting, number of patients who experienced vomiting; frequency of administration of antiemetic PRN medication dimenhydrinate) and safety (clinical and laboratory-chemical adverse events) of the prophylaxis regimens.

\section{Drug administration}

Ondansetron intravenous administration through a central venous catheter was started at least $30 \mathrm{~min}$ prior to the start of the first moderately or highly chemotherapeutic agent of each chemotherapy course at dosages of $8 \mathrm{mg}$ per $24 \mathrm{~h}$ in patients $\leq 15 \mathrm{~kg}$ bodyweight, $16 \mathrm{mg}$ per $24 \mathrm{~h}$ in patients of $>15-30 \mathrm{~kg}$ bodyweight, $24 \mathrm{mg}$ per 24 $\mathrm{h}$ in patients of $>30-45 \mathrm{~kg}$ bodyweight, and a maximum dose of $32 \mathrm{mg}$ per $24 \mathrm{~h}$ in patients with a bodyweight of $>45 \mathrm{~kg}$ as a 24-h continuous infusion over the whole time of intravenous chemotherapy administration until $24 \mathrm{~h}$ after the administration of the last agent of the respective course. Subsequently, the patients were supplied with ondansetron tablets or orally disintegrating tablets $(2 \times 2-8 \mathrm{mg}$ per day; adapted to the body surface area).

Fosaprepitant was started at least $1 \mathrm{~h}$ prior to the start of the first moderately or highly chemotherapeutic agent of each chemotherapy course as a single dose of $4.0 \mathrm{mg}$ per $\mathrm{kg}$ bodyweight (maximum $150 \mathrm{mg}$ ) as intravenous infusion through a central venous catheter over $30 \mathrm{~min}$.

Dimenhydrinate was provided as PRN medication through a central venous catheter infusion $(1.0 \mathrm{mg}$ per $\mathrm{kg}$ BW three times per day, max. $3 \times 62 \mathrm{mg}$ short infusion).

Breakthrough CINV was treated with dimenhydrinate (dosage $0.1 \mathrm{mg}$ per $\mathrm{kg}$ BW per day as $24 \mathrm{~h}$ infusion (max. $0.2 \mathrm{mg} / \mathrm{kg}$ per day BW)).

\section{Assessment of safety and tolerance}

The toxicity and adverse events grading of this analysis is based on the current United States National Cancer Institute's Common Terminology Criteria for Adverse Events [10]. Analyses of liver parameters, kidney parameters and electrolytes were performed on the day of in- 
patient admission before the first chemotherapy course and antiemetic prophylaxis (baseline), at least every other day during antiemetic prophylaxis during the inpatient stay (maximum or minimum), as well as on the day of clinical discharge (end), i.e. during the whole analysis period.

Liver parameters included alanine aminotransferase (ALT, normal range $\leq 39 \mathrm{U} / \mathrm{L}$ ) and aspartate aminotransferase (AST, normal range $\leq 59 \mathrm{U} / \mathrm{L}$ ), and the cholestasis parameter total bilirubin (normal range $\leq 1.1 \mathrm{mg} / \mathrm{dL}$ ). Kidney parameters included serum creatinine (normal range $\leq 0.7 \mathrm{mg} / \mathrm{dL}$ ) and urea (normal range $\leq 46 \mathrm{mg} / \mathrm{dL}$ ). Electrolytes included potassium (normal range $\geq 3.4$ $\mathrm{mmol} / \mathrm{L}$ - $4.9 \mathrm{mmol} / \mathrm{L}$ ), sodium (normal range 134 $\mathrm{mmol} / \mathrm{L}-145 \mathrm{mmol} / \mathrm{L})$, and calcium $(\geq 2.0 \mathrm{mmol} / \mathrm{L}-2.6$ $\mathrm{mmol} / \mathrm{L})$. Clinically-relevant elevations of $>1.5$ and $>2.5$ times the normal values of hepatic and kidney parameters, and decreases of potassium values $<3.4 \mathrm{mmol} / \mathrm{L}$ or $<2.4 \mathrm{mmol} / \mathrm{L}$, sodium values $<134 \mathrm{mmol} / \mathrm{L}$ and calcium values $<2.0 \mathrm{mmol} / \mathrm{L}$ were assessed. Maximum (ALT, AST, total bilirubin, creatinine, and urea) or minimum (potassium, sodium, calcium) values during the analysis period were used for comparisons with baseline values. Clinical potentially drug-related adverse events were analyzed during the application of fosaprepitant and compared between the two groups.

\section{Assessment of efficacy}

All patients were primarily monitored for the efficacy of the antiemetic prophylaxis regimen during the acute and delayed CINV phase of moderately and highly emetogenic chemotherapy courses. The vomiting frequency of the patients during the acute and delayed CINV phases and the number of administered doses of dimenhydrinate during all chemotherapy courses of both study cohorts was used as the measure for the efficacy analyses of both prophylaxis regimens. The relative number of patients experiencing vomiting and receiving dimenhydrinate was analyzed. The assessed parameters were analyzed and compared between the two study cohorts.

\section{Statistical analysis}

Chi-square-tests (with Yates' continuity correction) and Fisher's exact tests were used for 2-sample tests for equality of proportions and applied to the frequencies of clinical parameters in the two treatment groups (FG and CG). In addition, the package rateratio.test of $R$ was used to compare the frequency of the vomiting events between FG and CG [11].

The statistical comparison of the differences between the results and the normal range values for the liver and kidney parameters, as well as electrolytes, was performed by one-sample t-tests or one sample Wilcoxon signed rank tests (depending on the results of the Shapiro-Wilk normality test), taking into account the $95 \%$ confidence intervals $(\mathrm{CI})$.

The inferential statistical analysis between the baseline values, as well as the maximum and minimum values, was performed with the Wilcoxon matched pairs signed rank test. Differences were only considered to be significant if they were clinically relevant, i.e. significantly below (sodium, calcium and potassium) the reference values or above them (all other parameters).

Graphs and statistical tests were created with GraphPad Prism for Windows, version 7 (GraphPad Software Inc., La Jolla, CA, USA), or with $\mathrm{R}$ (The $\mathrm{R}$ Foundation for Statistical Computing, Institute for Statistics and Mathematics, Wirtschaftsuniversität Wien, Austria). $P$-values of $p<0.05\left(^{*}\right), p<0.01\left(^{* *}\right)$, $p<0.001$ (****) $^{(*)}$, and $p<0.0001{ }^{(* * * * * *)}$ ) were defined as statistically significant and are illustrated in the bar charts.

\section{Results}

\section{Patient characteristics}

A total of 79 pediatric patients were enrolled in this analysis. The median age at the first analyzed chemotherapy cycle was 8.0 years (range $0.5-17.9$ years) in all patients, 7.4 years (range 0.5-17.9 years) in the fosaprepitant group, and 8.3 years (range 0.6 year - 17.6 years) in the control group. A significant difference regarding age and gender could not be detected between the groups (Table 1). Of the 79 patients, $40(50.6 \%)$ received an antiemetic prophylaxis regimen with fosaprepitant and ondansetron and 39 (49.4\%) received ondansetron only, respectively.

\section{Analysis period}

The median period of analysis was 6 days (range 5-9 days) in both the fosaprepitant and the control group. In the fosaprepitant group, a total of 112 chemotherapy courses were administered, of which 84 courses $(75.0 \%)$ included moderately emetogenic agents and 28 courses (25.0\%) included highly emetogenic agents. In the control group, a total of 116 chemotherapy courses were administered, of which 89 courses (76.7\%) included moderately emetogenic agents and 27 courses (23.3\%) included highly emetogenic agents. The EPs of the administered chemotherapy courses did not significantly differ between the two groups ( $p=0.8812$; Table 2$)$. A median of 3 (range 3-4) chemotherapy courses were analyzed per patient in the fosaprepitant group and the control group. Thirty-six of the 40 patients of the fosaprepitant group $(90.0 \%)$ and 37 of the 39 patients of the control group (94.9\%) were observed during more than one moderately or highly emetogenic chemotherapy 
Table 1 Patient Characteristics

\begin{tabular}{|c|c|c|c|}
\hline \multirow[t]{3}{*}{ Patient Characteristics } & Fosaprepitant group & Control group & \multirow[t]{3}{*}{$p$-value } \\
\hline & $N=40$ & $N=39$ & \\
\hline & $n(\%)$ & $n(\%)$ & \\
\hline \multicolumn{4}{|l|}{ Age } \\
\hline$<2$ years & $5(12.5)$ & $5(12.8)$ & 0.7676 \\
\hline 2-6 years & $11(27.5)$ & $14(35.9)$ & 0.5752 \\
\hline $7-12$ years & $11(27.5)$ & $8(20.5)$ & 0.6432 \\
\hline $13-17$ years & $13(32.5)$ & $12(30.8)$ & 0.939 \\
\hline \multicolumn{4}{|l|}{ Sex } \\
\hline Male & $25(62.5)$ & $22(56.4)$ & \multirow[t]{2}{*}{0.7474} \\
\hline Female & $15(37.5)$ & $17(43.6)$ & \\
\hline \multicolumn{4}{|l|}{ Diagnosis } \\
\hline ALL & $10(25.0)$ & $8(20.5)$ & 0.8359 \\
\hline AML & $0(0.0)$ & $1(2.6)$ & 0.4937 \\
\hline ALL relapse & $2(5.0)$ & $2(5.1)$ & $>0.9999$ \\
\hline Astrocytoma & $1(2.5)$ & $1(2.6)$ & $>0.9999$ \\
\hline Non-Hodgkin Lymphoma & $4(10.0)$ & $5(12.8)$ & 0.737 \\
\hline Ependymoma & $1(2.5)$ & $1(2.6)$ & $>0.9999$ \\
\hline Ewing's sarcoma & $4(10.0)$ & $4(10.3)$ & $>0.9999$ \\
\hline Germinoma & $1(2.5)$ & $1(2.6)$ & $>0.9999$ \\
\hline Hepatoblastoma & $3(7.5)$ & $2(5.1)$ & $>0.9999$ \\
\hline Hodgkin's Lymphoma & $2(5.0)$ & $1(2.6)$ & $>0.9999$ \\
\hline Medulloblastoma & $2(5.0)$ & $1(2.6)$ & $>0.9999$ \\
\hline MDS & $1(2.5)$ & $0(0.0)$ & $>0.9999$ \\
\hline Nephroblastoma & $0(0.0)$ & $1(2.6)$ & 0.4937 \\
\hline Neuroblastoma & $3(7.5)$ & $3(7.7)$ & $>0.9999$ \\
\hline Osteosarcoma & $1(2.5)$ & $2(5.1)$ & $>0.9999$ \\
\hline Renal cell carcinoma & $0(0.0)$ & $1(2.6)$ & 0.4937 \\
\hline Rhabdomyosarcoma & $4(10.0)$ & $2(5.1)$ & 0.6752 \\
\hline T cell lymphoma & $1(2.5)$ & $3(7.7)$ & 0.3589 \\
\hline
\end{tabular}

A statistically significant difference of the patient characteristics between the two groups could not be detected ( $p>0.05$; Chi-square test with Yate's correction or Fisher's exact test)

Abbreviations: $A L L$ acute lymphoblastic leukemia, $A M L$ acute myeloid leukemia, $N$ total number of patients per cohort, $n$ sample size, MDS

myelodysplastic syndromes

course (total: $92.4 \%$ of the patients). None of the patients received dexamethasone.

\section{Efficacy analysis}

All 79 of the patients were included in the efficacy analysis. The relative number of patients experiencing vomiting during the acute and the delayed CINV phase during all 112 (FG) and 116 (CG) chemotherapy courses was significantly lower (acute phase: $p=0.0005 \mid$ delayed phase: $p=0.0017$ ) when receiving antiemetic prophylaxis with fosaprepitant and ondansetron $(n=10 ; 25.0 \%$ and $n=17 ; 42.5 \%$ respectively) compared with the patients receiving ondansetron only $(n=26 / 66.7 \%$ and $n=31$ / 79.5\%, respectively) (Fig. 1). Likewise, the relative number of chemotherapy courses, in which vomiting occurred was significantly higher in the control group when compared to the fosaprepitant group in both the acute CINV phase (CG: 45 of 116 courses (38.8\%) vs. FG: 21 of 112 courses (18.8\%); $p=0.0014)$ and the delayed CINV phase (CG: 66 of 116 courses (56.9\%) vs. FG: 41 of 112 courses $(36.6 \%) ; p=0.0033)$.

The vomiting frequency was significantly lower in patients with fosaprepitant and ondansetron prophylaxis with 37 events in the acute phase and 103 events in the delayed phase as opposed to 88 events in the acute phase $(p<0.0001)$ and 164 events in the delayed phase $(p<0.0001)$ for the control group. In the delayed phase, 62 of 103 vomiting events (60.2\%) of the fosaprepitant 
Table $\mathbf{2}$ Chemotherapy

\begin{tabular}{|c|c|c|c|c|c|}
\hline & Dosage & EP & Fosaprepitant group & Control group & $p$-value \\
\hline & & & $N=112$ courses & $N=116$ courses & \\
\hline & & & $n(\%)$ & $n(\%)$ & \\
\hline \multicolumn{6}{|l|}{ Agent } \\
\hline Carboplatin & & 4 & $8(7.1)$ & $8(6.9)$ & $>0.9999$ \\
\hline Cisplatin & & 4 & $5(4.5)$ & $8(6.9)$ & 0.5704 \\
\hline Clofarabine & & 3 & $0(0.0)$ & $1(0.9)$ & $>0.9999$ \\
\hline Cyclophosphamide & $\geq 1 \mathrm{~g} / \mathrm{m}^{2}$ & 4 & $2(1.8)$ & $2(1.7)$ & $>0.9999$ \\
\hline Cyclophosphamide & $<1 \mathrm{~g} / \mathrm{m}^{2}$ & 3 & $19(17.0)$ & $18(15.5)$ & 0.9072 \\
\hline Cytarabine & $>200 \mathrm{mg} / \mathrm{m}^{2}$ to $<3 \mathrm{~g} / \mathrm{m}^{2}$ & 3 & $16(14.3)$ & $11(9.5)$ & 0.3591 \\
\hline Dacarbazine & & 4 & $3(2.7)$ & $2(1.7)$ & 0.6793 \\
\hline Dactinomycin & & 4 & $9(8.0)$ & $7(6.0)$ & 0.6112 \\
\hline Daunorubicin & & 3 & 4 (3.6) & $10(8.6)$ & 0.1669 \\
\hline Doxorubicin & & 3 & $16(14.3)$ & $10(8.6)$ & 0.2555 \\
\hline Epirubicin & & 3 & $2(1.8)$ & $0(0.0)$ & 0.2402 \\
\hline Etoposide & & 3 & $28(25.0)$ & 25 (21.6) & 0.6459 \\
\hline Idarubicin & & 3 & $1(0.9)$ & $0(0.0)$ & 0.4912 \\
\hline Ifosfamide & & 3 & $17(15.2)$ & $12(10.3)$ & 0.3701 \\
\hline Irinotecan & & 3 & $0(0.0)$ & $2(1.7)$ & 0.498 \\
\hline Melphalan & $>50 \mathrm{mg} / \mathrm{m}^{2}$ & 3 & $1(0.9)$ & $1(0.9)$ & 1.0000 \\
\hline Methotrexate & $\geq 250 \mathrm{mg}$ to $<12 \mathrm{~g} / \mathrm{m}^{2}$ & 3 & $20(17.9)$ & $15(12.9)$ & 0.3965 \\
\hline Temozolomide & & 3 & $0(0.0)$ & $1(0.9)$ & $>0.9999$ \\
\hline Thiotepa & $\geq 300 \mathrm{mg} / \mathrm{m}^{2}$ & 4 & $1(0.9)$ & $0(0.0)$ & 0.4912 \\
\hline \multicolumn{6}{|l|}{ EP (CINV risk) } \\
\hline 3 (> 30-90\%) & & & $84(75.0)$ & 89 (76.7) & 0.8812 \\
\hline $4(>90 \%)$ & & & $28(25.0)$ & $27(23.3)$ & \\
\hline
\end{tabular}

The table shows the emetogenic potential (EP) of the administered chemotherapeutic agents in the fosaprepitant and the control group. EP was defined by the emetic risk (in \% frequency of emesis in absence of prophylaxis): minimal, stage $1(<10 \%) \mid$ low, stage $2(10-<30 \%) \mid$ moderate, stage $3(30-90 \%) \mid$ high, stage 4 (>90\%) [9]

Abbreviations: CINV chemotherapy-induced nausea and vomiting, EP emetogenic potential, $N$ total number of administered chemotherapy courses, $n$ sample size. The distribution of administered chemotherapeutic agents and the highest emetogenic potential of each chemotherapy course was not significantly different in both cohorts ( $p>0.05$; Chi-square test with Yate's correction or Fisher's exact test)

group and 105 of 164 vomiting events $(64.0 \%)$ occurred within the first $48 \mathrm{~h}$ of the delayed phase $(>24-72 \mathrm{~h}$ after chemotherapy administration).

A median of 3 (range 3-4) chemotherapy courses were analyzed per patient in the fosaprepitant group and the control group. Analyzing the courses in which vomiting occurred in the fosaprepitant, a median of two vomiting events (range 1-3) occurred during the acute and a median of three events (range 1-6) during the delayed CINV phase. In the control group, a median of two events (range 1-7) occurred in the acute and a median of four (range 1-21) in the delayed CINV phase.

Analyzing repeated cycles per patient in the fosaprepitant group, a median of two vomiting events (range 1-6) were registered in the first course administered to a patient. In the second course, a median of two (range 14 ), in the third course a median of two (range 1-6) and in the fourth course a median of two (range 1-5) vomiting events were registered. In the control group, a median of three vomiting events occurred in the first course (range 1-14), a median of two (range 1-21) in the second course, and median of three (range 2-8) in the third course and a median of three events (range 211 ) in the fourth course. In conclusion, vomiting frequencies did not increase or decrease within repeated chemotherapy courses in the same patients in both the fosaprepitant and the control group.

Overall, during both CINV phases $(0-120 \mathrm{~h}$ after chemotherapy administration), 140 vomiting events during 112 chemotherapy courses were observed in the 

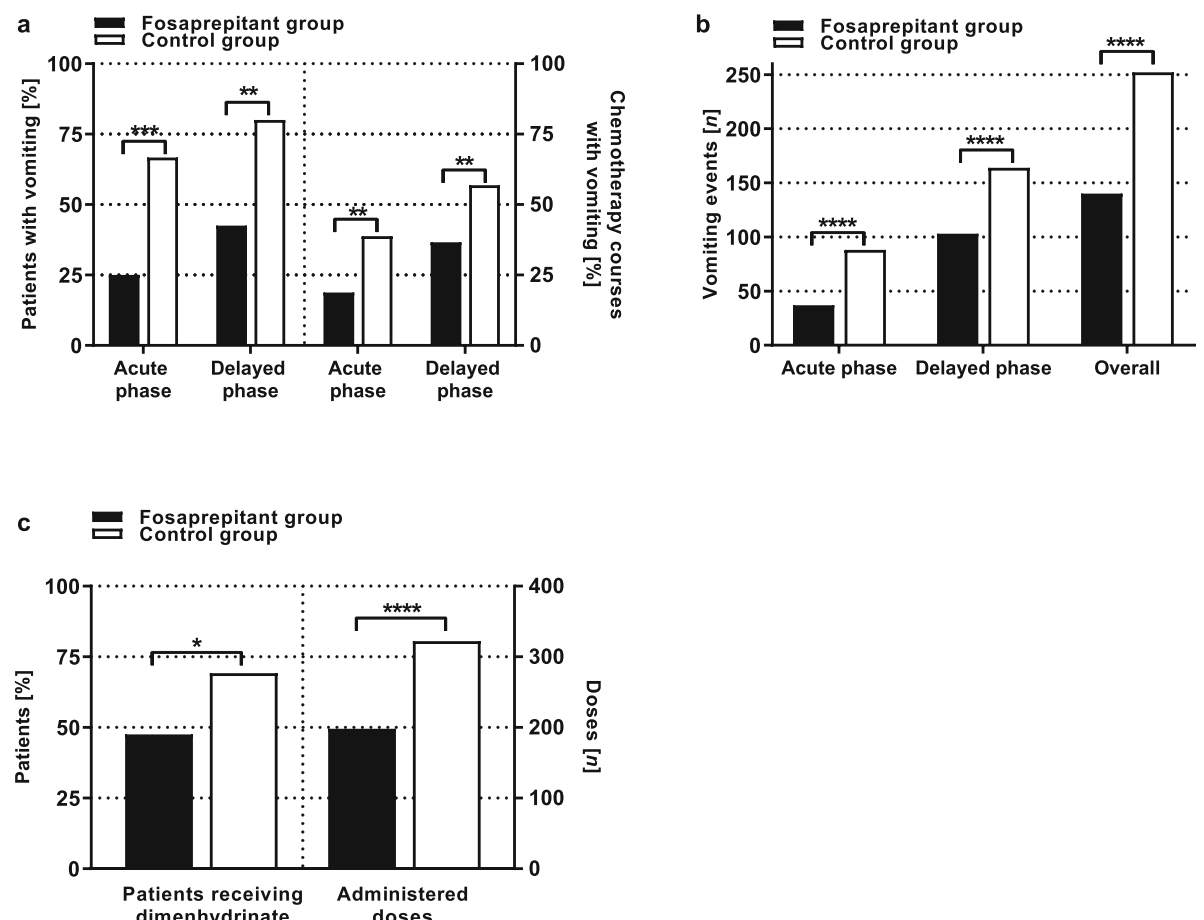

Fig. 1 Efficacy. The graph displays analyses of patients during moderately and highly emetogenic chemotherapy and CINV prophylaxis with ondansetron only (control group; 39 patients/116 chemotherapy courses; white bars) or with a combination of ondansetron and fosaprepitant (fosaprepitant group; 40 patients/112 chemotherapy courses; black bars). a. The percentage of patients experiencing vomiting was significantly higher in the control group during both the acute $(n=10 ; 25.0 \%$ vs. $n=26 ; 66.7 \% ; p=0.0005)$ and the delayed $(n=17 ; 42.5 \%$ vs. $n=31 ; 79.5 \%)$; $p=0.0017)$ CINV phase. Likewise, the number of chemotherapy courses in which vomiting occurred was significantly higher in the control group during both the acute $(n=45 ; 38.8 \%$ vs. $n=21 ; 18.8 \% ; p=0.0014)$ and the delayed ( $n=66 ; 56.9 \%$ vs. $n=41 ; 36.6 \%$ : $p=0.0033)$ CINV phase b. The total number of vomiting events during all chemotherapy courses of the respective cohort and both CINV phases was significantly higher in the control group when compared to the fosaprepitant group during the acute ( 88 vs. 37 events; $p<0.0001$ ) and the delayed CINV phase (164 vs. 103; $p<0.0001$ ), and during both CINV phases (252 vs. 140 events, $p=0.0001$ ). c. Significantly $(p=0.04884)$ fewer patients of the fosaprepitant group needed PRN medication with dimenhydrinate during both CINV phases compared with the control group $(47.5 \%, n=19$ vs. 69.2\%, $n=27)$. 1.6-fold fewer doses of dimenhydrinate were administered in the fosaprepitant group when compared to the control group during both CINV phases (198 vs. 322; $p<0.0001$ ). Symbols indicate *: $p<\left.0.05\right|^{* *}: p<\left.0.01\right|^{* * *}: p<\left.0.001\right|^{* * * *}: p<0.0001$

fosaprepitant group in comparison to 252 events during 116 chemotherapy courses in the control group (significantly different; $p<0.0001)$.

This effect could also be seen in the administered doses of additional PRN medication with dimenhydrinate during both CINV phases. Thus, the number of patients receiving dimenhydrinate during both CINV phases was significantly lower $(p=0.04884)$ in the fosaprepitant group $(n=$ $19 ; 47.5 \%)$ compared with the control group $(n=27$; $69.2 \%)$. Likewise, the number of chemotherapy courses during which dimenhydrinate was administered during both CINV phases was significantly higher $(p=0.0001)$ in the control group $(n=59 ; 50.9 \%)$ compared with the fosaprepitant group $(n=28 ; 25.0 \%)$. Among those courses, in which dimenhydrinate was administered, a median of 2 doses (range 1-21 doses; mean 7.1 \pm 6.4 doses) were administered in the control group and a median of 2 doses (range 1-12 doses; mean $3.3 \pm 3.0$ doses) were administered in the fosaprepitant group during both CINV phases. The total number of administered doses of dimenhydrinate during both CINV phases was significantly smaller $(p<0.0001)$ during prophylaxis with fosaprepitant and ondansetron $(n=198)$ compared with ondansetron only $(n=322)$ (Fig. $1 c)$.

\section{Safety and tolerance}

None of the 79 enrolled patients died during the analysis period. A discontinuation of the antiemetic medication was not indicated for any patient in either of the two groups.

During the analysis period, a significant increase of the hepatic parameter ALT could not be observed $(p>0.05)$ in either the control group (baseline: median $26 \mathrm{U} / \mathrm{L}$ | mean $30 \pm 16.3 \mathrm{U} / \mathrm{L}$ | range $8-80 \mathrm{U} / \mathrm{L}$; versus maximum: median $44 \mathrm{U} / \mathrm{L} \mid$ mean $52 \pm 42.5 \mathrm{U} / \mathrm{L} \mid$ range $10-176 \mathrm{U} / \mathrm{L}$ ) or the fosaprepitant group (baseline: median $21 \mathrm{U} / \mathrm{L}$ | 
mean $26 \pm 16.9 \mathrm{U} / \mathrm{L}$ | range $5-80 \mathrm{U} / \mathrm{L}$; versus maximum: median $34 \mathrm{U} / \mathrm{L} \mid$ mean $50 \pm 51.3 \mathrm{U} / \mathrm{L} \mid$ range $4-213 \mathrm{U} / \mathrm{L})$. Likewise, a significant increase of the hepatic parameter AST between baseline values and maximum values could not be observed $(p>0.05)$ in either the control group (baseline: median $34 \mathrm{U} / \mathrm{L} \mid$ mean $37 \pm 13.8 \mathrm{U} / \mathrm{L}$ | range 18-79 U/L; versus maximum: median $45 \mathrm{U} / \mathrm{L} \mid$ mean $55 \pm$ $40.3 \mathrm{U} / \mathrm{L}$ | range $11-180 \mathrm{U} / \mathrm{L}$ ) or the fosaprepitant group (baseline: median $28 \mathrm{U} / \mathrm{L} \mid$ mean $32 \pm 14.5 \mathrm{U} / \mathrm{L} \mid$ range $8-$ $78 \mathrm{U} / \mathrm{L}$; versus maximum: median $36 \mathrm{U} / \mathrm{L} \mid$ mean $53 \pm$ 42.1 U/L | range 12-187 U/L).

Increases of ALT and AST > 2.5 times the normal value occurred in both the fosaprepitant (6.3 and $0.9 \%$ of the patients, respectively) and the control group (6.9 and $2.6 \%$ of the patients, respectively), but were not significantly different $(p>0.5)$. Most probably, these increases are associated with the administered chemotherapy and not caused by the antiemetic medication with fosaprepitant or ondansetron (Table 3). All other analyzed laboratory parameters (total bilirubin, creatinine, urea, potassium, calcium and sodium) did not significantly or relevantly change during the observation period in either the control group or the fosaprepitant group (Fig. 2; Table 3).

Adverse events in the fosaprepitant group and the control group included exanthema, sweating, fever, loss of appetite, diarrhea, and obstipation. None of the patients in both study groups experienced neurological or anaphylactic adverse reactions or phlebitis of the fosaprepitant infusion site. The differences between the two groups were not statistically significant ( $p>0.05$; Table 3$)$.

Fosaprepitant was administered during 17 (15.2\%) of 112 courses of chemotherapy with ifosfamide within the first 3 months (November 2015 - January 2016) after the antiemetic prophylaxis regimen was changed to fosaprepitant. During these courses, we could not observe potentially drug-related neurological adverse events (Table 3).

\section{Discussion}

Dexamethasone is prohibited in several pediatric chemotherapy protocols $[5,6]$. Alternative or complementary antiemetic agents are needed for these patients. This non-interventional observation study is the first to report on the use of an antiemetic prophylaxis regimen consisting of single-dose intravenous fosaprepitant ( $\mathrm{NK}_{1} \mathrm{R}$ antagonist) at a dosage of $4 \mathrm{mg} / \mathrm{kg}$ bodyweight in combination with ondansetron (5- $\mathrm{HT}_{3} \mathrm{R}$ antagonist) 24$h$ continuous infusion without dexamethasone in pediatric patients between 0.5 and 17.9 years of age receiving moderately or highly emetogenic chemotherapy.

The results show a favorable efficacy of fosaprepitant combination therapy when compared with antiemetic prophylaxis with ondansetron only. Adverse events were not significantly higher in the fosaprepitant group compared with the control group. The intravenous administration of fosaprepitant was well-tolerated. Clinical drug-related side effects were similarly low in both groups. New or different safety issues were not observed in this study compared with previous studies with fosaprepitant in adult and pediatric patients [3, 4, 7, 12, 13].

In a randomized double-blinded phase III clinical trial with a total of 302 pediatric patients with a median age of 7 years ( $0.5-17.8$ years) receiving either oral aprepitant (up to $125 \mathrm{mg}$ as capsule or suspension, depending on age) or a placebo combined with ondansetron on the first day of moderately to very highly emetogenic chemotherapy followed by 2 days with antiemetic prophylaxis with aprepitant (up to $80 \mathrm{mg}$ ) or placebo only, the number of patients with complete control of CINV (absence of vomiting) in the delayed phase was significantly higher under aprepitant (51\%) compared with the placebo control group (26\%). Hepatic or renal laboratory parameters or electrolytes were not assessed in this study [14].

In a retrospective chart analysis, 35 pediatric patients with a median age of 10 years (range 10 months - 18 years) who received $4 \mathrm{mg} / \mathrm{kg}$ fosaprepitant (max. 150 $\mathrm{mg}$ ) in addition to an antiemetic prophylaxis regimen with ondansetron (100\% of the patients), dexamethasone (69\%), scopalamine (9\%), dronabinol (6\%), diphenhydramine $(3 \%)$ and/or lorazepam (3\%) for the prevention of CINV were analyzed. An absence of vomiting was observed in $89 \%$ of the patients during the acute and $63 \%$ in the delayed phase, and in $60 \%$ overall. In 12 of the 35 patients (34.2\%), elevation of the transaminases AST and ALT occurred. The authors hypothesized that these increases were mainly caused by methotrexate as part of the chemotherapy regimen. Other hepatic or renal laboratory parameters were not analyzed in this study. The results were not compared with a control cohort without fosaprepitant [15].

In a randomized, double-blind, placebo-controlled phase III single-center trial, the efficacy, safety and feasibility of an antiemetic prophylaxis regimen with fosaprepitant, ondansetron and dexamethasone compared with ondansetron and dexamethasone and a placebo were investigated. A total of 163 pediatric patients between 1 and 12 years of age were prospectively enrolled. The placebo group (median age: 5 years) received an intravenous prophylaxis regimen with ondansetron bolus $(1 \times 0.15-0.3 \mathrm{mg} / \mathrm{kg}$; max. $16 \mathrm{mg})$ plus dexamethasone $(1 \times 0.075 \mathrm{mg} / \mathrm{kg})$ and normal saline (placebo) before chemotherapy and oral ondansetron (total dose $0.3 \mathrm{mg} / \mathrm{kg}$ per $8 \mathrm{~h}$ ) and oral dexamethasone (total dose $0.15 \mathrm{mg} / \mathrm{kg}$ per $8 \mathrm{~h}$ ) during the $48 \mathrm{~h}$ after the last administration of emetogenic chemotherapy. The therapy group received the same regimen but $3 \mathrm{mg} /$ $\mathrm{kg}$ fosaprepitant in normal saline instead of the placebo. Complete absence of vomiting was significantly higher $(p<0.001)$ in the fosaprepitant group during the acute 
Table 3 Adverse reactions

$\begin{array}{ccc}\text { Fosaprepitant group } & \text { Control group } & p \text {-value } \\ N=112 \text { courses } & N=116 \text { courses } & \\ n(\%) & n(\%) & \end{array}$

Laboratory markers

Increase ALT (n.v. $\leq 39 \mathrm{U} / \mathrm{L}$ )

$\geq 1.5 \times$ normal value

$\geq 2.5 \times$ normal value

7 (6.3)

$7(6.3)$

Increase AST (n.v. $\leq 59 \mathrm{U} / \mathrm{L}$ )

$\geq 1.5 \times$ normal value

7 (6.3)

$\geq 2.5 \times$ normal value

$1(0.9)$

$1(0.9)$

$0(0.0)$

$0(0.0)$

$0(0.0)$

$1(0.9)$

$0(0.0)$

$\geq 2.5 \times$ normal value

Decrease potassium (n.v. $\geq 3.4 \mathrm{mmol} / \mathrm{L}-4.9 \mathrm{mmol} / \mathrm{L}$ )

$$
\begin{aligned}
& <3.4 \mathrm{mmol} / \mathrm{L} \\
& <2.4 \mathrm{mmol} / \mathrm{L}
\end{aligned}
$$

Decrease calcium (n.v. $\geq 2.0 \mathrm{mmol} / \mathrm{L}-2.6 \mathrm{mmol} / \mathrm{L}$ )

$$
\begin{array}{ll}
<2.0 \mathrm{mmol} / \mathrm{L} & 12(10.7) \\
<1.8 \mathrm{mmol} / \mathrm{L} & 0(0.0)
\end{array}
$$

Decrease sodium (n.v. 134-145 mmol/L)

$$
\begin{array}{ll}
<134 \mathrm{mmol} / \mathrm{L} & 14(12.5) \\
<130 \mathrm{mmol} / \mathrm{L} & 2(1.8)
\end{array}
$$

23 (19.8)

Adverse reactions

$\begin{array}{ll}\text { Exanthema } & 1(0.9) \\ \text { Sweating } & 3(2.7) \\ \text { Fever } & 5(4.5) \\ \text { Loss of appetite } & 3(2.7) \\ \text { Diarrhea } & 15(13.4) \\ \text { Obstipation } & 4(3.6)\end{array}$

Obstipation

The occurrence of clinical and laboratory adverse reactions was not significantly different $(p>0.05)$ between both study groups

Abbreviations: ALT alanine aminotransferase, AST aspartate aminotransferase, $\mathrm{mg} / \mathrm{dL}$ milligram per deciliter, $\mathrm{mmol} / \mathrm{L}$ millimol per liter, $n$ sample size, $n . v$. normal value, No. number, $U / L$ Units per liter

CINV phase (86\% versus 60\%), the delayed CINV phase (79\% versus $51 \%$ ) and both CINV phases (70\% versus 41\%) compared with the control group [4]. The distinctly worse results in our control group are most likely ascribed to the prophylaxis regimen without dexamethasone compared with the results of the study by Radhakrishnan et al., emphasizing the importance of dexamethasone as a crucial element in CINV prophylaxis. However, the comparison of the two studies' results regarding their fosaprepitant groups gives rise to the question whether a double prophylaxis with fosaprepitant and ondansetron might be similarly effective as a triple prophylaxis with additional dexamethasone. This might be of great importance for pediatric patients receiving chemotherapy during which dexamethasone is prohibited. However, this hypothesis must be analyzed in future prospective trials. 


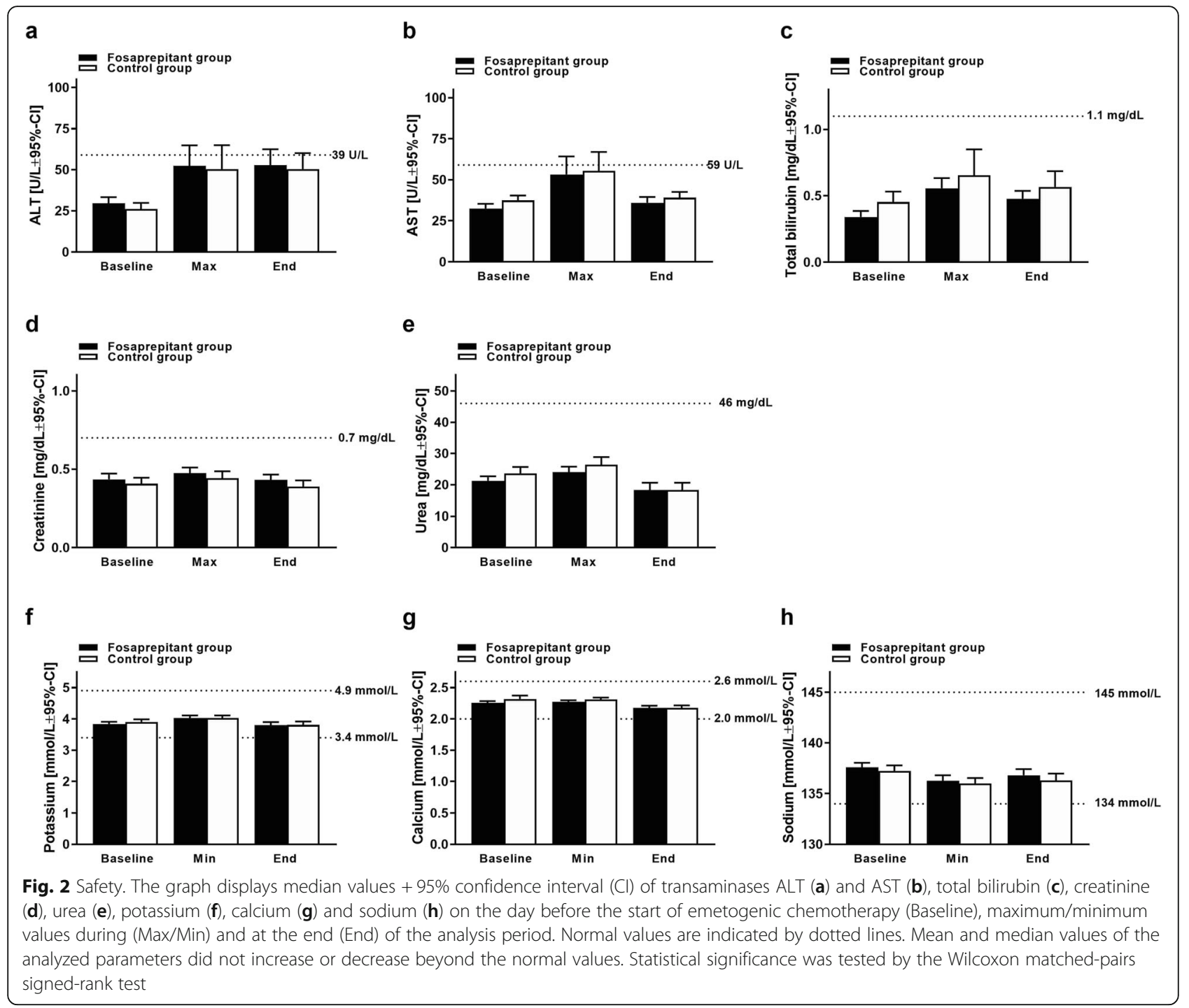

\section{Conclusions}

The data provided in this non-interventional observation study indicate that antiemetic prophylaxis with singledose intravenous fosaprepitant in addition to a 24-h continuous infusion of ondansetron without dexamethasone was safe and effective as CINV prophylaxis in pediatric patients between 0.5 and 17.9 years of age receiving moderately or highly emetogenic chemotherapy. The prophylaxis regimen with fosaprepitant and ondansetron was significantly favorable compared with the monoprophylaxis with ondansetron only in both the acute and the delayed CINV phase. Potentially drug-related adverse events of fosaprepitant could not be observed in this analysis. Larger prospective trials are necessary to evaluate our findings.

\section{Abbreviations}

5- $\mathrm{HT}_{3} \mathrm{R}$ : 5-hydroxytryptamine-3 receptor; ALL: Acute lymphoblastic leukemia; AML: Acute myeloid leukemia; CG: Control group; Cl: Confidence interval;
CINV: Chemotherapy induced nausea and vomiting; FG: Fosaprepitant group; IV: Intravenous; L: Liter; MASCC/ESMO: Multinational Association of Supportive Care in Cancer/European Society for Medical Oncology; mg/ $\mathrm{dL}$ : Milligram per deciliter; $\mathrm{mg} / \mathrm{m}^{2}$ : Milligram per square meter body surface area; $\mathrm{mmol} / \mathrm{L}$ : Millimol per liter; $n$ : Sample size; n.d.: Not determined; n.v.: Normal value; NCCN: US National Comprehensive Cancer Network; $N K_{1} R$ : Neurokinin-1 receptor; No.: Number; p: P-value, probability value; SD: Standard deviation; U/L: Units per liter; vs.: Versus

\section{Acknowledgements}

Not applicable.

\section{Authors' contributions}

$M D$, TF and SW were responsible for the conception and design of this study. SW, KMCS, MH, VB, FB, JF, TF and MD collected data. SW, TF, MD and KMCS analyzed and interpreted the data. MD and KMCS wrote the manuscript. SW, KMCS, MH, VB, FB, JF, TF and MD were substantially involved in the drafting and/or critical revision of the manuscript. SW, KMCS, MH, VB, $F B, J F$, TF and MD read and approved the final manuscript.

\section{Funding}

The authors received financial support (funding of human resources/research staff) from the Bettina-Bräu-Stiftung, Fürstenfeldbruck, Germany. The funding 
body had no role in the in the design of the study and collection, analysis, and interpretation of data and in writing the manuscript.

\section{Availability of data and materials}

The datasets used and/or analyzed during the current study are available from the corresponding author on reasonable request.

\section{Ethics approval and consent to participate}

This non-interventional observation study was performed under the waiver of the Ethics Committee of the Ludwig-Maximilians-University Munich (ReNo. 18-764) and in accordance Helsinki declaration. This is a noninterventional observation study. In accordance with the directive 2001/20/ EC of the European Parliament and of the council of 4 April 2001 on the approximation of the laws, regulations and administrative provisions of the member states relating to the implementation of good clinical practice in the conduct of clinical trials on medical products for human use, formal informed consent of the patients and an ethics vote of the institutional ethics committee are not required [16]. Baseline demographics, clinical factors, and survival rates were abstracted from clinical and research records on all patients and maintained on a prospective basis.

\section{Consent for publication}

Not applicable.

\section{Competing interests}

The authors declare that they have no competing interests.

\section{Author details}

'Dr.-von-Hauner'sches Kinderspital, Paediatric Haematology, Oncology and Stem Cell Transplantation, Ludwig-Maximilians-University München, 80337 Munich, Germany. Department I - General Paediatrics, Haematology/ Oncology, University Children's Hospital Tübingen, Hoppe-Seyler-Str. 1, 72076 Tübingen, Germany.

Received: 3 May 2019 Accepted: 10 October 2019

Published online: 15 November 2019

\section{References}

1. Navari RM. Management of chemotherapy-induced nausea and vomiting in pediatric patients. Paediatric drugs. 2017;19(3):213-22.

2. Aapro M, Carides A, Rapoport BL, Schmoll HJ, Zhang L, Warr D. Aprepitant and fosaprepitant: a 10-year review of efficacy and safety. Oncologist. 2015; 20(4):450-8

3. Okumura LM, D'Athayde Rodrigues F, Ferreira MAP, Moreira LB. Aprepitant in pediatric patients using moderate and highly emetogenic protocols: a systematic review and meta-analyses of randomized controlled trials. $\mathrm{Br} J$ Clin Pharmacol. 2017:83(5):1108-17.

4. Radhakrishnan V, Joshi A, Ramamoorthy J, Rajaraman S, Ganesan P, Ganesan TS, et al. Intravenous fosaprepitant for the prevention of chemotherapyinduced vomiting in children: A double-blind, placebo-controlled, phase III randomized trial. Pediatr Blood Cancer. 2019;66(3):e27551. https://doi.org/10. 1002/pbc.27551. Epub 2018 Nov 13

5. Roila F, Molassiotis A, Herrstedt J, Aapro M, Gralla RJ, Bruera E, et al. 2016 MASCC and ESMO guideline update for the prevention of chemotherapy- and radiotherapy-induced nausea and vomiting and of nausea and vomiting in advanced cancer patients. Ann Oncol. 2016; 27(suppl_5):v119-v33.

6. Einhorn LH, Rapoport B, Navari RM, Herrstedt J, Brames MJ. 2016 updated MASCC/ESMO consensus recommendations: prevention of nausea and vomiting following multiple-day chemotherapy, high-dose chemotherapy, and breakthrough nausea and vomiting. Support Care Cancer. 2017;25(1):303-8.

7. Shillingburg A, Biondo L. Aprepitant and fosaprepitant use in children and adolescents at an academic medical center. J Pediatr Pharmacol Therapeut. 2014;19(2):127-31

8. US Food and Drug Administration. EMEND - Fosaprepitant Dimeglumine NDA 022023 - SUPPL-17 2018 [FDA Approval]. Available from: https://www. fda.gov/downloads/Drugs/DevelopmentApprovalProcess/ DevelopmentResources/UCM605696.pdf. Accessed 1 May 2019.

9. Dupuis LL, Boodhan S, Sung L, Portwine C, Hain R, McCarthy P, et al. Guideline for the classification of the acute emetogenic potential of antineoplastic medication in pediatric cancer patients. Pediatr Blood Cancer. 2011;57(2):191-8.

10. U.S. NIH - NCl. Common Terminology Criteria for Adverse Events v4.03 (CTCAE) 2010. 2010 May 28, 2009.

11. Fay M. Two-sided exact tests and matching confidence intervals for discrete data. R J. 2010;2(1):53-8

12. Grunberg S, Chua D, Maru A, Dinis J, DeVandry S, Boice JA, et al. Singledose fosaprepitant for the prevention of chemotherapy-induced nausea and vomiting associated with cisplatin therapy: randomized, double-blind study protocol--EASE. J Clin Oncol. 2011;29(11):1495-501.

13. Saito H, Yoshizawa H, Yoshimori K, Katakami N, Katsumata N, Kawahara M, et al. Efficacy and safety of single-dose fosaprepitant in the prevention of chemotherapy-induced nausea and vomiting in patients receiving highdose cisplatin: a multicentre, randomised, double-blind, placebo-controlled phase 3 trial. Ann Oncol. 2013;24(4):1067-73.

14. Kang HJ, Loftus S, Taylor A, DiCristina C, Green S, Zwaan CM. Aprepitant for the prevention of chemotherapy-induced nausea and vomiting in children: a randomised, double-blind, phase 3 trial. Lancet Oncol. 2015;16(4):385-94.

15. Timaeus S, Elder J, Franco K. Evaluation of the use of Fosaprepitant for the prevention of chemotherapy-induced nausea and vomiting in pediatric patients. J Pediatr Hematol Oncol. 2018;40(7):527-31.

16. Directive 2001/20/EC of the European Parliament and of the councol of 4 April 2001 on the approximation of the laws, regulations and administrative provisions of the Member States relating to the implementation of good clinical practice in the conduct of clinical trials on medical products for human use, 2001/20/EC. Sect. OJ L 121 (2001).

\section{Publisher's Note}

Springer Nature remains neutral with regard to jurisdictional claims in published maps and institutional affiliations.

Ready to submit your research? Choose BMC and benefit from:

- fast, convenient online submission

- thorough peer review by experienced researchers in your field

- rapid publication on acceptance

- support for research data, including large and complex data types

- gold Open Access which fosters wider collaboration and increased citations

- maximum visibility for your research: over $100 \mathrm{M}$ website views per year

At BMC, research is always in progress.

Learn more biomedcentral.com/submission 